\title{
Erradicação de fungos em germoplasma vegetal importado
}

\author{
Marta Aguiar Sabo Mendes(1), Arailde Fontes Urben ${ }^{(1)}$, \\ Vilmar Gonzaga( ${ }^{(1)}$ e Flávia Lopes Fernandes Mattos ${ }^{(2)}$
}

\begin{abstract}
(1)Embrapa Recursos Genéticos e Biotecnologia, Núcleo de Gestão da Estação Quarentenária de Germoplasma Vegetal, Parque Estação Biológica, Avenida W5 Norte (Final), CEP 70770-917 Brasília, DF, Brasil. E-mail: marta.mendes@embrapa.br, arailde.urben@embrapa.br, vilmar.gonzaga@embrapa.br (2)Embrapa Quarentena Vegetal, Parque Estação Biológica, Avenida W3 Norte (Final), CEP 70770-901 Brasília, DF, Brasil. E-mail: flavia.marques@embrapa.br
\end{abstract}

Resumo - O objetivo deste trabalho foi avaliar os métodos utilizados para a erradicação dos fungos exóticos detectados em germoplasma vegetal importado. Foram utilizadas metodologias convencionais adaptadas na Estação Quarentenária Vegetal Nível 1, da Embrapa Recursos Genéticos e Biotecnologia. No período de 1977 a 2013, foram analisados aproximadamente 300.000 acessos de germoplasma, procedentes de mais de 90 países, pertencentes a mais de 330 produtos diferentes. Dos 37 fungos exóticos detectados, destacam-se quatro espécies quarentenárias que pertencem à Lista de Pragas Quarentenárias Ausentes: Tilletia indica, Phoma exigua var. foveata, Periconia circinata e Dactuliochaeta glycines (Syn. Phoma glycinicola). As medidas fitossanitárias realizadas foram efetivas para a interceptação/erradicação desses patógenos. As metodologias empregadas são fundamentais para a liberação de material genético livre de pragas exóticas e favorecem o enriquecimento genético dos programas de melhoramento do Sistema Nacional de Pesquisa Agropecuária.

Termos para indexação: fungos exóticos, fungos quarentenários, interceptação de pragas, quarentena, segurança biológica.

\section{Eradication of fungi in imported plant germplasm}

\begin{abstract}
The objective of this work was to evaluate the methods used for the eradication of exotic fungi detected in imported plant germplasm. Adapted standard methodologies were used in a level 1 plant quarantine station, located at Embrapa Recursos Genéticos e Biotecnologia, in Brazil. From 1977 to 2013, about 300,000 germplasm accessions from more than 90 countries, from more than 330 different products, were examined. Of the 37 detected exotic fungi, this study highlights four quarantine species belonging to a list of absent quarantine pests: Tilletia indica, Phoma exigua var. foveata, Periconia circinata, and Dactuliochaeta glycines (Syn. Phoma glycinicola). The phytosanitary measures conducted were effective for the interception/ eradication of these pathogens. The methodologies used are crucial for the release of genetic material free of exotic pests and favor genetic enrichment of improvement programs of the Sistema Nacional de Pesquisa Agropecuária, the national agricultural research system.
\end{abstract}

Index terms: exotic fungi, quarantine fungi, interception of pests, quarantine, biosafety.

\section{Introdução}

A agricultura brasileira tem-se beneficiado da introdução de germoplasma, que permitiu ao País obter variedades adaptadas às nossas condições edafoclimáticas, resistentes a pragas e mais produtivas. Graças aos programas de melhoramento genético e ao germoplasma introduzido, o Brasil aumentou, nas últimas décadas, sua produtividade em mais de $200 \%$ por hectare para a maioria dos produtos do agronegócio, como soja, milho, arroz, algodão e diversas forrageiras, florestais, frutíferas e hortaliças, o que elevou significativamente a nossa balança comercial (Albuquerque \& Silva, 2008; Intercâmbio..., 2012).

O movimento internacional de produtos vegetais envolve riscos de introdução de pragas. Importações inadvertidas causaram sérios prejuízos no passado à agricultura no mundo. $\mathrm{O}$ exemplo mais marcante ocorreu no século XIX, com a introdução do fungo Plasmopara viticola, agente etiológico do míldio da videira, na Europa, por meio de mudas importadas dos Estados Unidos (Gessler et al., 2011). Todos os países vitivinicultores sofreram as consequências da doença, 
especialmente a França. No Brasil, a ferrugem do cafeeiro, causada pelo fungo Hemileia vastatrix Berk $\&$ Br., introduzida em 1970, causou perdas em torno de 30\% na produção nacional (Fernandes et al., 2009). Recentemente, a sigatoka-negra da bananeira, causada por Mycosphaerella fijiensis Morelet, foi introduzida e provocou perdas de até $100 \%$ na produção de bananas na região Norte (Martins et al., 2007). A ferrugem asiática da soja, cujo agente etiológico é Phakopsora pachyrhizi Syd. \& P. Syd., foi registrada em 2001 e causou perdas de até $70 \%$ na produção de soja (Yorinori \& Lazzarotto, 2004). A ferrugem alaranjada da cana-de-açúcar, cujo agente etiológico é Puccinia kuehnii (W. Krüger) E.J. Butler, foi introduzida em 2010 e causou perdas importantes na produção de açúcar e álcool (Tibolla et al., 2012).

Toda a movimentação de germoplasma vegetal destinado ao Sistema Nacional de Pesquisa Agropecuária (SNPA) está sob legislação específica do Ministério da Agricultura, Pecuária e Abastecimento (Mapa) (Brasil, 1934). O Mapa, por meio da Portaria $n^{o}$ 11, de 15/2/2002 (Brasil, 2002), credenciou o Laboratório de Quarentena Vegetal (LQV) da Embrapa Recursos Genéticos e Biotecnologia como Estação Quarentenária Vegetal Nível 1 (EQVN1), para os procedimentos legais exigidos no intercâmbio do material para pesquisa no País.

A quarentena é a forma mais eficiente, econômica e sustentável de controle de pragas. As ações de quarentena se fortaleceram após a instalação da Organização Mundial do Comércio (OMC), em 1995. As barreiras tarifárias foram substituídas pelas barreiras fitossanitárias. Os impostos ou taxas, exigidos para a importação e exportação de produtos agrícolas, deram lugar às exigências fitossanitárias, que incluem análises de risco de pragas (ARP) e outras, como a quarentena.

O objetivo deste trabalho foi descrever os métodos utilizados para a erradicação dos fungos exóticos detectados em germoplasma vegetal importado.

\section{Material e Métodos}

O Laboratório de Micologia da Estação Quarentenária Vegetal Nível 1 (EQVN1), da Embrapa Recursos Genéticos e Biotecnologia, no período de 1977 a 2013, analisou aproximadamente 300.000 acessos de germoplasma procedentes de mais de 90 países (Figura 1). Os países que mais enviaram material genético para o Brasil foram: Estados Unidos
(43\%), México (24\%), Colômbia (13\%), Filipinas (4\%), Argentina (2\%), Tailândia (2\%), o Estado norte-americano do Havaí (1\%), Uruguai (1\%), Chile (1\%) e França (1\%). Foram analisados mais de 330 produtos diferentes, e milho (Zea mays L.), soja (Glycine max (L.) Merr.), trigo (Triticum sp. L.), arroz (Oryza sativa L.), triticale (X. triticosecale Wittmack), feijão (Phaseolus vulgaris L.), cevada (Hordeum vulgare L.), algodão (Gossypium hirsutum L.), sorgo (Sorghum bicolor (L.) Moench) e girassol (Helianthus annuus L.) apresentaram os maiores números de entrada de acessos (Figura 2).

Os métodos utilizados para análise do material vegetal foram aplicados de acordo com o tipo de material importado, sementes ou material de propagação vegetativa, como mudas, estacas ou tubérculos. Para a detecção de fungos em sementes, foram utilizados dois métodos. O método de plaqueamento em papel de filtro ("blotter test") (PP) foi utilizado para a detecção dos fungos que crescem bem em meio de cultura (a maioria dos fungos), como os gêneros Alternaria, Colletotrichum, Bipolaris e Phoma. Para a detecção de fungos que não se desenvolvem bem em meio de cultura, como os que causam ferrugem e carvão, foi utilizado o método de lavagem das sementes seguido de sedimentação. O método de plantio em quarentenário ("growing-on") (PQ) foi empregado para a detecção de fungos em germoplasma de sementes, mudas e estacas, pela observação de sintomas em plantas ou plântulas, plaqueamento em meio de cultura (BDA), câmara

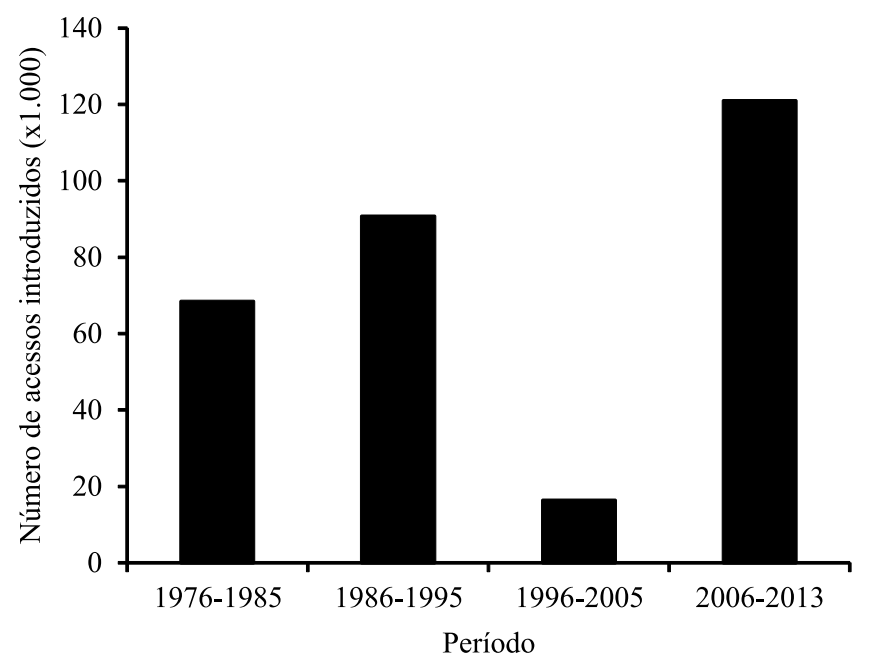

Figura 1. Número de acessos de germoplasma introduzido no Brasil no período de 1976 a 2013. 
úmida e exame direto sob microscópio estereoscópico. A identificação das espécies/gêneros foi realizada pelo método morfológico, sob microscópio estereoscópico e de luz. Todos os métodos acima citados foram de acordo com o descrito em Mendes \& Ferreira (1994) e Marinho et al. (2003).

A erradicação de fungos exóticos, não registrados no Brasil, foi realizada empregando-se metodologia convencional de tratamento químico com fungicida de ação sistêmica (Carbendazim) e de contato (Tiram) (Henning, 2005). A forma de aplicação dos fungicidas variou de acordo com o tipo de material importado, sementes ou propagação vegetativa.

Para a confirmação da eficiência dos tratamentos, após os tratamentos, todo o germoplasma foi submetido a métodos de "avaliação da erradicação". Os métodos foram ajustados de acordo com a biologia do fungo, o método de detecção e o índice de contaminação. Antes do tratamento do germoplasma semente, todo o material foi previamente examinado retirando-se todas as sementes com manchas, murchas ou fora do padrão.

Para germoplasma com fungos detectados pelo método de PP e índice de contaminação abaixo de $1,0 \%$, a confirmação da erradicação do patógeno, após tratamento, foi realizada pelo método de PP. O período

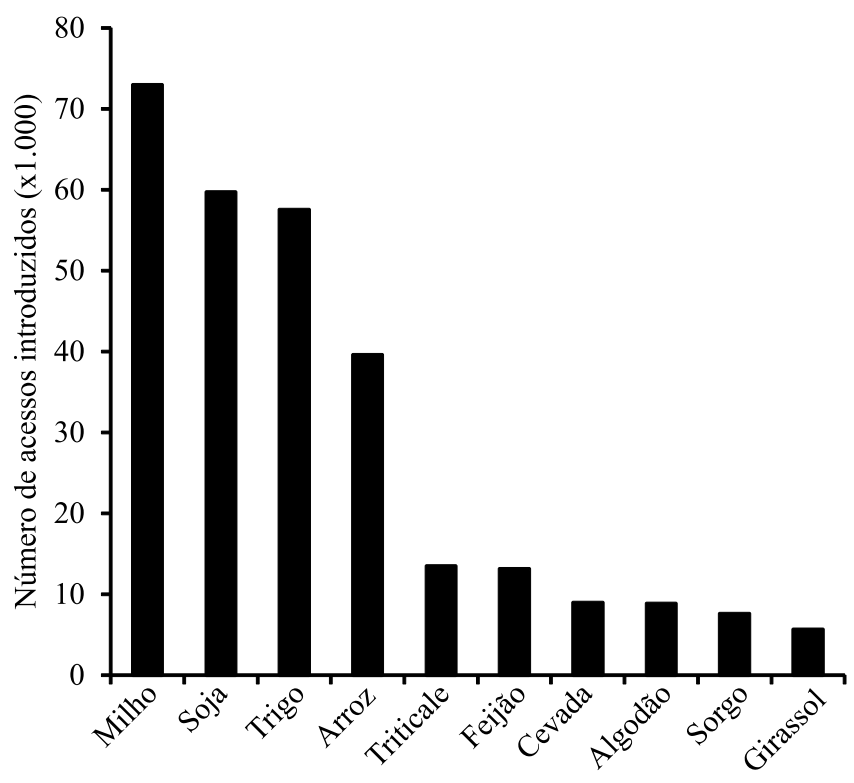

Figura 2. Principais produtos analisados pelo Laboratório de Micologia da Estação Quarentenária Vegetal nível 1, da Embrapa Recursos Genéticos e Biotecnologia, no período de 1976-2013. de incubação foi alterado de 7-10 dias para 15-20 dias. O germoplasma com índice de contaminação acima de $1,0 \%$, para maior confiabilidade da erradicação do patógeno, a reanalise foi em BDA. As sementes foram colocadas em placas de Petri, três sementes por placa e após o período de incubação de 5 a 7 dias, apenas as sementes seguramente sem sinais de fungos, foram liberadas para o plantio. O restante do material foi autoclavado, antes de ser descartado.

Para a erradicação de fungos exóticos detectados pelo método de $\mathrm{PQ}$, o tratamento químico foi por meio de pulverizações com Carbendazim e Tiram, de 15 em 15 dias, até que as mudas não apresentassem quaisquer sinais ou sintomas de fungos. Durante esse período, mínimo de seis meses, em que as plantas permaneceram no quarentenário, foram cuidadosamente acompanhadas para a remoção das folhas/hastes com lesões. Após a confirmação da ausência do patógeno, o germoplasma permaneceu no quarentenário por mais três meses, para a confirmação da erradicação da praga.

Todo germoplasma de trigo procedente do México, enviado para o Brasil, em virtude do risco da introdução de Tilletia indica, foi submetido ao tratamento específico na origem, conforme descrito a seguir. Primeiramente as sementes mais leves, que têm maiores chances de estarem contaminadas por fungos, foram retiradas por meio de separação por ventilação. A seguir as sementes foram tratadas quimicamente com os fungicidas, Carbendazin + Tiram. Amostras representativas, que não receberam os tratamentos citados, foram retiradas para as análises fitossanitárias realizadas na EQVN1.

A erradicação de praga exótica de Phoma exigua var. foveata em tubérculos de batata foi realizada por meio da imersão em calda com os mesmos fungicidas, sistêmico e de contato. Após o tratamento, os tubérculos foram plantados em quarentenário, por três gerações, para confirmar a erradicação do patógeno.

Os dados foram tabulados e organizados em planilhas, com a indicação da presença ou ausência do patógeno, uma vez que o único resultado satisfatório para a liberação foi o de erradicação das pragas exóticas analisadas.

\section{Resultados e Discussão}

Foram interceptados 37 fungos no período de 1977 a 2013, sendo quatro espécies de fungos quarentenários,

Pesq. agropec. bras., Brasília, v.51, n.5, p.473-482, maio 2016 DOI: 10.1590/S0100-204X2016000500007 
que pertencem à Lista de Pragas Quarentenárias Ausentes (Brasil, 2007) (Tabela 1), 18 espécies exóticas, ausentes não regulamentadas (Tabela 2), 12 gêneros/espécies não relatados na cultura analisada (Tabelas 3 e 4), e três espécies que possuem raças não relatadas no Brasil (Tabela 5).

Das espécies interceptadas, Tilletia indica Mitra, Phoma exigua var.foveata (Foister) Boerema, Periconia circinata (L. Mangin) Sacc. e Dactuliochaeta glycines (R. B. Stewart) G. L. Hartm. and J. B. Sinclair (Sin. Pyrenochaeta glycines R.B. Stewart.) são espécies regulamentadas pela legislação fitossanitária brasileira como pragas quarentenárias. Tilletia indica, agente etiológico do carvão parcial do trigo (Karnal bunt), foi detectado em germoplasma procedente do México e erradicado antes do estabelecimento no Brasil. A detecção do patógeno ocorreu quando as infecções ainda não haviam se manifestado. Apenas foram detectados os esporos dos fungos, em laboratório, sem apresentar lesões visíveis. Nos locais onde foi detectado este fungo, não foram cultivados trigo ou outras espécies hospedeiras de $T$. indica, por 4 anos. Essa medida fitossanitária, provavelmente, auxiliaram no não estabelecimento da doença no Rio Grande do Sul. O patógeno não foi detectado novamente no território nacional (Mendes et al., 2010). Tilletia indica causa a descoloração dos grãos e reduz sua produtividade e qualidade, por transmitir um odor desagradável para os seus derivados. Lotes de trigo com 3,0\% de grãos infectados são considerados insatisfatórios para o consumo humano (Agarwal et al., 2004; Sansford et al., 2008).
As ações quarentenárias nos Estados Unidos não foram suficientes para impedir a entrada do $T$. indica naquele país (IMI..., 1996). Em 2013, esse patógeno foi erradicado dos estados da Califórnia e do Novo México, porém, continua presente no Arizona (North American Plant Protection Organizations, 2013).

Para a erradicação de Phoma exigua var. foveata, agente etiológico da gangrena da batata, ou potato gangrene, ou tuber rot, os tubérculos foram tratados com Carbendazim + Tiram e plantados em quarentenário, por três gerações. Esse fungo foi bastante disseminado na Europa, com distribuição restrita nas Américas, Ásia e África (Smith et al., 1997; Mendes et al., 2004). Causa a podridão de tubérculos, principalmente em condições de armazenamento, sob temperatura baixa. $\mathrm{Na}$ Europa, verificou-se também que o patógeno ataca as hastes da planta (Mordue, 1981).

A erradicação de $P$. circinata, detectado no germoplasma de cevada procedente do México, foi obtida por meio do tratamento químico das sementes e confirmada pela reanálise em papel de filtro. O fungo foi detectado a $0,03 \%$, nível baixíssimo de infecção. A partir de sua introdução nos Estados Unidos, esse patógeno disseminou-se rapidamente pelos principais estados produtores de sorgo, tendo-se tornado, na década de 1980, uma doença importante no sudoeste dos EUA, com perdas de 50-60\% quando variedades susceptíveis foram plantadas em solos infestados (Ellis, 1968; Dunkle, 1986). A partir da década de 1980, foram desenvolvidas variedades resistentes a esse patógeno (Nagy \& Bennetzen, 2008).

Dactuliochaeta glycines, sinônimo de Phoma glycinicola Gruyter \& Boerema, interceptado em

Tabela 1. Fungos quarentenários ausentes, detectados e erradicados na Estação Quarentenária de Germoplasma Vegetal da Embrapa Recursos Genéticos e Biotecnologia, no período de 1976 a 2013.

\begin{tabular}{|c|c|c|c|c|c|c|}
\hline Fungo & Procedência & Hospedeira & Tipo de material & $\begin{array}{l}\text { Situação da praga no Brasil } \\
\text { no ano da interceptação }\end{array}$ & $\begin{array}{l}\text { Situação atual da } \\
\text { praga no Brasil }\end{array}$ & $\begin{array}{l}\text { Métodos de } \\
\text { erradicação }\end{array}$ \\
\hline Periconia circinata & México & $\begin{array}{l}\text { Cevada } \\
\text { (Hordeum vulgare) }\end{array}$ & $\begin{array}{l}\text { Semente/ } \\
\text { germoplasma }\end{array}$ & Quarentenário ausente & $\begin{array}{l}\text { Quarentenário } \\
\text { ausente }\end{array}$ & Tratamento $^{(1)}$ \\
\hline $\begin{array}{l}\text { Phoma exigua var. } \\
\text { foveata }\end{array}$ & França & $\begin{array}{l}\text { Batata } \\
\text { (Solanum tuberosum) }\end{array}$ & $\begin{array}{l}\text { Tubérculo/ } \\
\text { germoplasma }\end{array}$ & Quarentenário ausente & $\begin{array}{l}\text { Quarentenário } \\
\text { ausente }\end{array}$ & Tratamento $^{(2)}$ \\
\hline $\begin{array}{l}\text { Dactuliochaeta } \\
\text { glycines (Sin. Phoma } \\
\text { glycinicola) }\end{array}$ & Nigéria & $\begin{array}{l}\text { Soja } \\
\text { (Glycine max) }\end{array}$ & $\begin{array}{l}\text { Semente/ } \\
\text { germoplasma }\end{array}$ & Quarentenário ausente & $\begin{array}{l}\text { Quarentenário } \\
\text { ausente }\end{array}$ & Tratamento $^{(1)}$ \\
\hline Tilletia indica & $\begin{array}{l}\text { Uruguai e } \\
\text { México }\end{array}$ & $\begin{array}{l}\text { Trigo } \\
\text { (Triticum aestivum) }\end{array}$ & $\begin{array}{l}\text { Semente/ } \\
\text { germoplasma }\end{array}$ & Quarentenário ausente & $\begin{array}{l}\text { Quarentenário } \\
\text { ausente }\end{array}$ & Tratamento $^{(3)}$ \\
\hline
\end{tabular}

${ }^{(1)}$ Tratamento químico, seguido de reanálise em plaqueamento em papel de filtro. ${ }^{(2)}$ Tratamento químico de tubérculos, seguido de plantio e reanálise.

${ }^{(3)}$ Tratamento químico e peneiramento das sementes, na origem. 
germoplasma de soja procedente da Nigéria, foi erradicado das sementes pelo mesmo método utilizado para $P$. circinata. As perdas na produção de soja causadas por D. glycines em países da África, como Zâmbia, Zimbábue e Etiópia, foram entre 7\% e 50\%, dependendo da cultivar (Mekonen \& Dilnesaw, 2014). $\mathrm{Na}$ África, a importância dessa doença aumentou junto com o crescimento da produção de soja (Mendes et al., 2004).
Dezoito espécies de fungos fitopatogênicos não regulamentadas pela legislação fitossanitária, exóticos para o Brasil, foram detectadas no germoplasma vegetal importado (Tabela 2). Todas essas espécies, exceto Colletotrichum capsici (Syd. \& P. Syd.) E.J. Butler \& Bisby, permanecem exóticas ao Brasil. Colletotrichum capsici foi relatada nas culturas de Bougainvillea sp., Capsicum annuum e Jatropha spp. (Mendes et al., 2010).

Tabela 2. Fungos não regulamentados, ausentes no Brasil, detectados e erradicados na Estação Quarentenária de Germoplasma Vegetal da Embrapa Recursos Genéticos e Biotecnologia, no período de 1976 a 2013.

\begin{tabular}{|c|c|c|c|c|c|c|}
\hline Fungo & Procedência & Hospedeira & Tipo de material & $\begin{array}{l}\text { Situação da praga } \\
\text { no Brasil no ano da } \\
\text { interceptação }\end{array}$ & $\begin{array}{l}\text { Situação atual da } \\
\text { praga no Brasil }\end{array}$ & $\begin{array}{l}\text { Métodos de } \\
\text { erradicação }\end{array}$ \\
\hline $\begin{array}{l}\text { Alternaria } \\
\text { chrysanthemi }\end{array}$ & Dinamarca & $\begin{array}{c}\text { Crisântemo } \\
\text { (Chrysanthemum sp.) }\end{array}$ & $\begin{array}{c}\text { Sementes } / \text { material } \\
\text { comercial }\end{array}$ & Ausente & Ausente & ${\text { Incineração } 0^{(1)}}$ \\
\hline Bipolaris euphorbiae & França & $\begin{array}{c}\text { Forrageira } \\
\text { (Penninsetum sp.) }\end{array}$ & $\begin{array}{c}\text { Sementes/ } \\
\text { germoplasma }\end{array}$ & Ausente & Ausente & Tratamento $^{(2)}$ \\
\hline Cercospora carthami & Estados Unidos & $\begin{array}{c}\text { Cártamo } \\
\text { (Carthamus tinctorius) }\end{array}$ & $\begin{array}{c}\text { Sementes/ } \\
\text { germoplasma }\end{array}$ & Ausente & Ausente & $\begin{array}{l}\text { Material não } \\
\text { liberado }^{(3)}\end{array}$ \\
\hline Colletotrichum capsici & Taiwan & $\begin{array}{c}\text { Pimentão } \\
\text { (Capsicum annuum) }\end{array}$ & $\begin{array}{c}\text { Sementes/ } \\
\text { germoplasma }\end{array}$ & Ausente & Relatado no Brasil & Tratamento $^{(2)}$ \\
\hline $\begin{array}{l}\text { Colletotrichum } \\
\text { linicola }\end{array}$ & Estados Unidos & $\begin{array}{c}\text { Linhaça } \\
\text { (Linum usitatissimun) }\end{array}$ & $\begin{array}{c}\text { Sementes/ } \\
\text { germoplasma }\end{array}$ & Ausente & Ausente & Tratamento $^{(4)}$ \\
\hline Coniothyrium oleae & Israel & $\begin{array}{c}\text { Oliveira } \\
\text { (Olea europaea) }\end{array}$ & $\begin{array}{c}\text { Mudas/ } \\
\text { germoplasma }\end{array}$ & Ausente & Ausente & Tratamento $^{(5)}$ \\
\hline $\begin{array}{l}\text { Cylindrocarpon } \\
\text { obtusisporum }\end{array}$ & Itália & $\begin{array}{c}\text { Videira } \\
\text { (Vitis vinifera) }\end{array}$ & $\begin{array}{c}\text { Estacas/ } \\
\text { germoplasma }\end{array}$ & Ausente & Ausente & Tratamento $^{(5)}$ \\
\hline Drechslera biseptata & Bulgária & $\begin{array}{c}\text { Triticale } \\
\text { (Triticosecale Wittmack) }\end{array}$ & $\begin{array}{c}\text { Sementes/ } \\
\text { germoplasma }\end{array}$ & Ausente & Ausente & Tratamento $^{(2)}$ \\
\hline Drechslera biseptata & Chile & $\begin{array}{c}\text { Trigo } \\
\text { (Triticum aestivum) }\end{array}$ & $\begin{array}{c}\text { Sementes/ } \\
\text { germoplasma }\end{array}$ & Ausente & Ausente & Tratamento $^{(2)}$ \\
\hline Drechslera mediocris & Estados Unidos & $\begin{array}{c}\text { Milheto } \\
\text { (Pennisetum typhoides) }\end{array}$ & $\begin{array}{c}\text { Sementes/ } \\
\text { germoplasma }\end{array}$ & Ausente & Ausente & Tratamento $^{(2)}$ \\
\hline $\begin{array}{l}\text { Lophodermium } \\
\text { seditiosum }\end{array}$ & Estados Unidos & $\begin{array}{c}\text { Pinus } \\
(\text { Pinus taeda) }\end{array}$ & $\begin{array}{c}\text { Mudas/ } \\
\text { germoplasma }\end{array}$ & Ausente & Ausente & Tratamento $^{(5)}$ \\
\hline Phomopsis cucurbitae & Estados unidos & $\begin{array}{c}\text { Melão } \\
\text { (Cucumis melo) }\end{array}$ & $\begin{array}{l}\text { Sementes/ } \\
\text { germoplasma }\end{array}$ & Ausente & Ausente & Tratamento $^{(2)}$ \\
\hline Phomopsis diospyri & Estados Unidos & $\begin{array}{c}\text { Caqui } \\
\text { (Diospyros caki) }\end{array}$ & $\begin{array}{c}\text { Mudas/ } \\
\text { germoplasma }\end{array}$ & Ausente & Ausente & Tratamento $^{(5)}$ \\
\hline $\begin{array}{l}\text { Phomopsis } \\
\text { malvacearum }\end{array}$ & França & $\begin{array}{c}\text { Algodão } \\
\text { (Gossypium hirsutum) }\end{array}$ & $\begin{array}{c}\text { Sementes/ } \\
\text { germoplasma }\end{array}$ & Ausente & Ausente & Tratamento $^{(2)}$ \\
\hline $\begin{array}{l}\text { Phomopsis } \\
\text { oryzae-sativae }\end{array}$ & Estados Unidos & $\begin{array}{c}\text { Arroz } \\
\text { (Oryza sativa) }\end{array}$ & $\begin{array}{l}\text { Sementes/ } \\
\text { germoplasma }\end{array}$ & Ausente & Ausente & Tratamento $^{(2)}$ \\
\hline Phomopsis tectonae & Malásia & $\begin{array}{c}\text { Teca } \\
\text { (Tectonae grandis) }\end{array}$ & $\begin{array}{l}\text { Sementes/ } \\
\text { germoplasma }\end{array}$ & Ausente & Ausente & Tratamento $^{(2)}$ \\
\hline Phyllosticta panizzei & Israel & $\begin{array}{c}\text { Oliveira } \\
\text { (Olea europaea) }\end{array}$ & $\begin{array}{c}\text { Mudas/ } \\
\text { germoplasma }\end{array}$ & Ausente & Ausente & Tratamento $^{(5)}$ \\
\hline $\begin{array}{l}\text { Pleospora } \\
\text { papaveracea }\end{array}$ & Itália & $\begin{array}{c}\text { Oliveira } \\
\text { (Olea europaea) }\end{array}$ & $\begin{array}{c}\text { Mudas/ } \\
\text { germoplasma }\end{array}$ & Ausente & Ausente & Tratamento $^{(5)}$ \\
\hline $\begin{array}{l}\text { Seimatosporium } \\
\text { lonicerae }\end{array}$ & Estados Unidos & $\begin{array}{c}\text { Videira } \\
\text { (Vitis vinifera) }\end{array}$ & $\begin{array}{c}\text { Mudas/ } \\
\text { germoplasma }\end{array}$ & Ausente & Ausente & Tratamento ${ }^{(5)}$ \\
\hline
\end{tabular}

${ }^{(1)}$ Incineração do material vegetal comercial pelo Ministério da Agricultura, Pecuária e Abastecimento. ${ }^{(2)}$ Tratamento químico, seguido de reanálise em plaqueamento em papel de filtro. ${ }^{(3)}$ Tratamento químico, seguido de reanálise pelo método de plantio em quarentenário. Não erradicou a praga. Germoplasma não liberado. ${ }^{(4)}$ Tratamento químico, seguido de reanálise em plaqueamento em meio BDA. ${ }^{(5)}$ Tratamento químico de mudas, seguido de reanálise. 
Tabela 3. Espécies de fungos, não relatadas no Brasil na cultura analisada, detectadas e interceptadas na Estação Quarentenária de Germoplasma Vegetal da Embrapa Recursos Genéticos e Biotecnologia, no período de 1976 a 2013. O tratamento utilizado para interceptação da praga no Brasil foi químico, seguido de reanálise em plaqueamento em papel de filtro.

\begin{tabular}{|c|c|c|c|c|c|}
\hline Fungo & Procedência & Hospedeira & Tipo de material & $\begin{array}{l}\text { Situação da praga no Brasil no } \\
\text { ano da interceptação }\end{array}$ & $\begin{array}{c}\text { Situação atual da praga } \\
\text { no Brasil }\end{array}$ \\
\hline Drechslera australiensis & Colômbia & $\begin{array}{c}\text { Arroz } \\
\text { (Oryza sativa) }\end{array}$ & $\begin{array}{l}\text { Sementes / } \\
\text { germoplasma }\end{array}$ & Ausente & Não ocorre nesta cultura \\
\hline Drechslera australiensis & $\begin{array}{l}\text { Estados Unidos, } \\
\text { México e Argentina }\end{array}$ & $\begin{array}{c}\text { Trigo } \\
\text { (Triticum aestivum) }\end{array}$ & $\begin{array}{l}\text { Sementes / } \\
\text { germoplasma }\end{array}$ & Não ocorre nesta cultura & Não ocorre nesta cultura \\
\hline Drechslera australiensis & Estados Unidos & $\begin{array}{c}\text { Cevada } \\
\text { (Hordeum vulgare) }\end{array}$ & $\begin{array}{l}\text { Sementes / } \\
\text { germoplasma }\end{array}$ & Não ocorre nesta cultura & Não ocorre nesta cultura \\
\hline Drechslera australiensis & Índia & $\begin{array}{c}\text { Milheto } \\
\text { (Pennisetum typhoides) }\end{array}$ & $\begin{array}{c}\text { Sementes / } \\
\text { germoplasma }\end{array}$ & Não ocorre nesta cultura & Não ocorre nesta cultura \\
\hline Drechslera hawaiiensis & Índia & $\begin{array}{c}\text { Sorgo } \\
\text { (Sorghum bicolor) }\end{array}$ & $\begin{array}{l}\text { Sementes / } \\
\text { germoplasma }\end{array}$ & Ausente & Não ocorre nesta cultura \\
\hline Drechslera hawaiiensis & Colômbia & $\begin{array}{c}\text { Arroz } \\
\text { (Oryza sativa) }\end{array}$ & $\begin{array}{c}\text { Sementes / } \\
\text { germoplasma }\end{array}$ & Não ocorre nesta cultura & Não ocorre nesta cultura \\
\hline Drechslera hawaiiensis & México & $\begin{array}{c}\text { Cevada } \\
\text { (Hordeum vulgare) }\end{array}$ & $\begin{array}{l}\text { Sementes / } \\
\text { germoplasma }\end{array}$ & Não ocorre nesta cultura & Não ocorre nesta cultura \\
\hline Drechslera hawaiiensis & China & $\begin{array}{c}\text { Arroz } \\
\text { (Oryza sativa) }\end{array}$ & $\begin{array}{l}\text { Sementes / } \\
\text { germoplasma }\end{array}$ & Não ocorre nesta cultura & Não ocorre nesta cultura \\
\hline Drechslera hawaiiensis & Austrália & $\begin{array}{c}\text { Panicum } \\
\text { (Panicum sp.) }\end{array}$ & $\begin{array}{l}\text { Sementes / } \\
\text { germoplasma }\end{array}$ & Não ocorre nesta cultura & Não ocorre nesta cultura \\
\hline Drechslera hawaiiensis & Honduras & $\begin{array}{c}\text { Caliandra } \\
\text { (Calliandra calothyrsus) }\end{array}$ & $\begin{array}{l}\text { Sementes / } \\
\text { germoplasma }\end{array}$ & Não ocorre nesta cultura & Não ocorre nesta cultura \\
\hline Fusarium acuminatum & Colômbia & $\begin{array}{c}\text { Brachiaria } \\
\text { (Brachiaria } \text { sp.) }\end{array}$ & $\begin{array}{l}\text { Sementes / } \\
\text { germoplasma }\end{array}$ & Não ocorre nesta cultura & Não ocorre nesta cultura \\
\hline $\begin{array}{l}\text { Phaeotrichoconis } \\
\text { crotalariae }\end{array}$ & Austrália & Eucalipto (Eucalyptus sp.) & $\begin{array}{c}\text { Sementes / } \\
\text { germoplasma }\end{array}$ & Não ocorre nesta cultura & Não ocorre nesta cultura \\
\hline
\end{tabular}

Tabela 4. Gêneros de fungos não relatados na cultura analisada, no Brasil, detectados e interceptados na Estação Quarentenária de Germoplasma Vegetal da Embrapa Recursos Genéticos e Biotecnologia, no período de 1976 a 2013.

\begin{tabular}{|c|c|c|c|c|c|c|}
\hline Fungo & Procedência & Hospedeira & Tipo de material & $\begin{array}{l}\text { Situação da praga } \\
\text { no Brasil no ano da } \\
\text { interceptação }\end{array}$ & $\begin{array}{l}\text { Situação atual da } \\
\text { praga no Brasil }\end{array}$ & $\begin{array}{l}\text { Interceptação da } \\
\text { praga no Brasil }\end{array}$ \\
\hline Botrytis sp. & Itália & $\begin{array}{c}\text { Açafrão } \\
\text { (Crocus sativus) }\end{array}$ & Bulbos/germoplasma & $\begin{array}{c}\text { Não ocorre nesta } \\
\text { cultura }\end{array}$ & $\begin{array}{c}\text { Não ocorre nesta } \\
\text { cultura }\end{array}$ & Tratamento $^{(1)}$ \\
\hline Cephalosporium sp. & Estados Unidos & $\begin{array}{c}\text { Graviola } \\
\text { (Annona sp.) }\end{array}$ & Sementes/germoplasma & $\begin{array}{l}\text { Não ocorre nesta } \\
\text { cultura }\end{array}$ & $\begin{array}{l}\text { Não ocorre nesta } \\
\text { cultura }\end{array}$ & Tratamento $^{(2)}$ \\
\hline Clasterosporium sp. & Filipinas & $\begin{array}{c}\text { Arroz } \\
\text { (Oryza sativa) }\end{array}$ & Sementes/germoplasma & $\begin{array}{l}\text { Não ocorre nesta } \\
\text { cultura }\end{array}$ & $\begin{array}{l}\text { Não ocorre nesta } \\
\text { cultura }\end{array}$ & Tratamento $^{(2)}$ \\
\hline Cytospora sp. & Estados Unidos & $\begin{array}{c}\text { Pínus } \\
\text { (Pinus } \text { spp.) }\end{array}$ & Sementes/germoplasma & $\begin{array}{l}\text { Não ocorre nesta } \\
\text { cultura }\end{array}$ & $\begin{array}{l}\text { Não ocorre nesta } \\
\text { cultura }\end{array}$ & Tratamento $^{(2)}$ \\
\hline Didymosphaeria sp. & Paraguai & $\begin{array}{l}\text { Sorgo (Sorghum } \\
\text { bicolor) }\end{array}$ & Sementes/germoplasma & $\begin{array}{l}\text { Não ocorre nesta } \\
\text { cultura }\end{array}$ & $\begin{array}{l}\text { Não ocorre nesta } \\
\text { cultura }\end{array}$ & Tratamento $^{(2)}$ \\
\hline Leptosphaeria sp. & Bélgica & $\begin{array}{c}\text { Arroz } \\
\text { (Oryza sativa) }\end{array}$ & Sementes/germoplasma & $\begin{array}{l}\text { Não ocorre nesta } \\
\text { cultura }\end{array}$ & $\begin{array}{l}\text { Não ocorre nesta } \\
\text { cultura }\end{array}$ & Tratamento $^{(2)}$ \\
\hline Mycosphaerella sp. & Estados Unidos & $\begin{array}{c}\text { Soja } \\
\text { (Glycine max })\end{array}$ & Sementes/germoplasma & $\begin{array}{l}\text { Não ocorre nesta } \\
\text { cultura }\end{array}$ & $\begin{array}{l}\text { Não ocorre nesta } \\
\text { cultura }\end{array}$ & Tratamento $^{(2)}$ \\
\hline Septoria sp. & Itália & $\begin{array}{c}\text { Videira } \\
\text { (Vitis vinifera) }\end{array}$ & $\begin{array}{l}\text { Estacas/material } \\
\text { comercial }\end{array}$ & $\begin{array}{l}\text { Não ocorre nesta } \\
\text { cultura }\end{array}$ & $\begin{array}{l}\text { Não ocorre nesta } \\
\text { cultura }\end{array}$ & Incineração $^{(3)}$ \\
\hline
\end{tabular}

${ }^{(1)}$ Tratamento químico de tubérculos, seguido de plantio e reanálise. ${ }^{(2)}$ Tratamento químico, seguido de reanálise em plaqueamento em papel de filtro.

${ }^{(3)}$ Incineração do material vegetal comercial pelo Ministério da Agricultura, Pecuária e Abastecimento. 
Os métodos utilizados para a erradicação foram eficientes para todas as espécies, com exceção de C. carthami detectado em germoplasma de cártamo (Carthamus tinctorius). Esse patógeno foi detectado pelo método de plantio em quarentenário. A incidência foi de $100 \%$ das plantas analisadas, com alta taxa de virulência. O tratamento apenas reduziu o índice da doença, sem a erradicação do patógeno, não tendo sido possível liberar esse material. $\mathrm{O}$ cártamo pode ser utilizado na produção de agroenergia, sendo C. carthami considerado o patógeno mais sério dessa cultura, causando perdas de quase $80 \%$ (Lartey et al., 2007).

Entre as espécies quarentenárias não regulamentadas erradicadas, podemos destacar Colletotrichum linicola Pethybr. \& Laff., detectado em 49\% dos acessos (Tabela 2). Foi erradicado de sementes de germoplasma de linhaça (Linum usitatissimum L.) procedentes dos Estados Unidos (Gruzdevienè et al., 2008). Colletotrichum linicola, agente etiológico da antracnose, representa uma ameaça para a cultura da linhaça no País, tendo em vista que pode causar danos de até $90 \%$ nas variedades mais susceptíveis e que possui 25 raças fisiológicas diferentes (Tomm, 2005). A espécie Phomopsis oryzae-sativae Punith. (sin. Ascochyta oryzae Catt.), detectada em sementes de germoplasma de arroz procedente dos Estados Unidos, é um risco para a cultura do arroz, mas possui a distribuição geográfica muito restrita no mundo (Interactive..., 2015). Lophodermium seditiosum Minter, Staley \& Millar foi erradicado de acículas de Pinus taeda, um dos maiores problemas fitossanitários dessa cultura (Hanso \& Drenkhan, 2012).
Os patógenos relacionados nas Tabelas 3 e 4 estão presentes no Brasil, mas são exóticos para as culturas analisadas. Com exceção do gênero Clasterosporium, que não há registro em nenhuma cultura, no País (Mendes et al., 2010). Esses patógenos causam danos nas plantas hospedeiras analisadas, em outros locais no mundo, como o patógeno Mycosphaerella sp., detectado em soja, agente causal da mancha das folhas em soja, relatado na Malásia (Williams \& Liu, 1976) e nos EUA, no estado do Mississipi (Miller \& Roy, 1982). O tratamento químico, nas diversas formas de aplicação e reanálises, foram eficientes para a erradicação dos patógenos e envio dos materiais aos destinatários, com exceção dos materiais comerciais (amostras fiscais): Vitis sp. infectado com Septoria sp.; crisântemo infectado com Alternaria chrysanthemi Crosier \& Heit, Fusarium solani (Mart.) Sacc.; e amarílis (Amaryllis sp. L.) com Fusarium solani (Mart.) Sacc. (Tabela 4). Esses materiais foram incinerados. A incineração tem sido uma das medidas fitossanitárias empregadas para os materiais comerciais contaminados com pragas exóticas.

Das três espécies de fungos que possuem raças não relatadas no Brasil (Tabela 5), foi possível erradicar apenas Phoma lingam (Tode) Desm. em germoplasma de canola (Brassica spp.) com o tratamento químico e reanálise pelo método de BDA e plantio de sementes limpas. $P$. lingam, agente causal da canela-preta (blackleg), desde o final da década de 1990 passou a ser a principal doença da canola no Brasil (Tomm, 2005). Os danos causados por esse patógeno estão diretamente relacionados às condições climáticas favoráveis e à presença de isolados de maior ou menor

Tabela 5. Espécies de fungos, que possuem raças ou grupos de anastomoses, não relatados no Brasil, detectados e interceptados na Estação Quarentenária de Germoplasma Vegetal da Embrapa Recursos Genéticos e Biotecnologia, no período de 1976 a 2013.

\begin{tabular}{|c|c|c|c|c|c|c|}
\hline Fungo & Procedência & Hospedeira & Tipo de material & $\begin{array}{l}\text { Situação da praga } \\
\text { no Brasil no ano da } \\
\text { interceptação }\end{array}$ & $\begin{array}{c}\text { Situação atual da } \\
\text { praga no Brasil }\end{array}$ & $\begin{array}{l}\text { Interceptação da } \\
\text { praga no Brasil }\end{array}$ \\
\hline Fusarium solani & Holanda & $\begin{array}{c}\text { Amarílis } \\
\text { (Amaryllis sp.) }\end{array}$ & $\begin{array}{c}\text { Sementes/ } \\
\text { material comercial }\end{array}$ & $\begin{array}{l}\text { Possui raças não } \\
\text { relatadas }\end{array}$ & $\begin{array}{l}\text { Possui raças não } \\
\text { relatadas }\end{array}$ & Incineração ${ }^{(1)}$ \\
\hline Phoma lingam & Austrália & $\begin{array}{c}\text { Canola } \\
\text { (Brassica } \text { spp.) }\end{array}$ & $\begin{array}{c}\text { Sementes/ } \\
\text { germoplasma }\end{array}$ & $\begin{array}{l}\text { Possui raças não } \\
\text { relatadas }\end{array}$ & $\begin{array}{l}\text { Possui raças não } \\
\text { relatadas }\end{array}$ & Tratamento $^{(2)}$ \\
\hline Rhizoctonia solani & Estados Unidos & $\begin{array}{c}\text { Soja } \\
\text { (Glycine max) }\end{array}$ & $\begin{array}{c}\text { Sementes } \\
\text { /germoplasma }\end{array}$ & $\begin{array}{l}\text { Possui grupos de } \\
\text { anastomoses não } \\
\text { relatados }\end{array}$ & $\begin{array}{l}\text { Possui grupos de } \\
\text { anastomoses não } \\
\text { relatados }\end{array}$ & Incineração $^{(1)}$ \\
\hline
\end{tabular}

${ }^{(1)}$ Incineração do material vegetal comercial pelo Ministério da Agricultura, Pecuária e Abastecimento. ${ }^{(2)}$ Métodos de erradicação da praga: tratamento químico, seguido de reanálise em plaqueamento em meio BDA. 
virulência, podendo ser inferiores a $2 \%$ ou superiores a $50 \%$, quando os isolados são mais agressivos (Thomas, 1984). A Índia também interceptou $P$. lingam pelo risco de introdução de raças fisiológicas exóticas (Agarwal et al., 2004).

O germoplasma de soja, procedente dos Estados Unidos, infectado com $R$. solani, foi incinerado em virtude da dificuldade de erradicação do patógeno e do risco de introdução de variabilidade genética. Embora essa espécie de praga seja relatada no Brasil em mais de 50 espécies diferentes de plantas, inclusive na soja, a introdução de um novo isolado de $R$. solani representa uma ameaça às variedades cultivadas no País. É importante considerar que a variabilidade desse patógeno é altíssima (Bernardes-de-Assis et al., 2009), e não se pode correr o risco de introduzir genótipos distintos dos que são relatados no País. Tem-se como exemplo uma população de $R$. solani AG-1 IA, presente no Brasil, adaptada ao milho na Venezuela (González-Vera et al., 2010). Essa população não ocorre no Brasil. A doença mancha bandeada do milho ainda é exótica para o País. Embora se trate de AG-1 IA, relatado no arroz e na soja, a introdução desse genótipo adaptado ao milho representa risco à agricultura brasileira.

O patógeno $F$. solani possui 47 formas especiais ou variedades diferentes, segundo Commonwealth Agricultural Bureaux International (CABI) (2009). Em cada uma dessas variações fisiológicas, são relatadas inúmeras raças fisiológicas de maior ou menor virulência (Chiorato et al., 2006).

Dependendo da espécie do patógeno, novas raças podem causar danos superiores aos de uma espécie exótica introduzida em um país. Atualmente, a raça Ug99 da espécie Puccinia graminis f. tritici Erikss. \& Henning e suas mutações são a maior ameaça à produção mundial de trigo, pois não há fonte de resistência genética a essa raça, sendo uma grande ameaça ao cultivo de trigo no mundo (Chaves et al., 2008; Stone, 2010).

Em virtude da complexidade desses patógenos, não é viável, em estação quarentenária, a caracterização deles no que diz respeito a variedade, forma especial ou raça, para considerar sua presença ou ausência em um país. Recomenda-se, portanto, a erradicação do patógeno ou a incineração do material vegetal quando são detectadas espécies de fungos com registros de variabilidade genética. Isso se deve aos riscos de introduzir novas raças de patógenos, que, em muitos casos, são mais virulentos e podem quebrar a resistência das variedades cultivadas no país, além de não serem controlados com os fungicidas registrados (Manninger, 2008). A erradicação de pragas é sempre uma forma que possibilita aos programas de melhoramento receber um material de difícil aquisição e livre de pragas exóticas ao País.

\section{Conclusões}

1. Os métodos utilizados para a erradicação dos fungos exóticos detectados em germoplasma vegetal importado são efetivos para interceptação/erradicação de fungos ausentes regulamentados ou não.

2. O método de reanálise em BDA, seguido de plantio apenas de sementes sem sinais ou sintomas de fungos, é uma forma totalmente segura de internalizar no País germoplasma raro.

3. A decisão sobre o método a ser utilizado para a erradicação depende da espécie/gênero, do tipo de material, da semente ou de propagação vegetativa e do nível de infecção.

\section{Referências}

AGARWAL, P.C; SINGH, B.; DEV, U.; RANI, I.; DINESH, C.; JOSHI, K.D; MAURYA, A.K.; KHETARPAL, R.K. Pathogenic fungi intercepted in introduced germplasm during 2001. Indian Journal of Agricultural Sciences, v. 74,p. 451-454, 2004.

ALBUQUERQUE, A.C.S.; SILVA, A.G. da (Ed.). Agricultura tropical: quatro décadas de inovações tecnológicas, institucionais e políticas. Brasília: Embrapa Informação Tecnológica, 2008. v.1.

BERNARDES-DE-ASSIS, J.; STORARI, M.; ZALA, M.; WANG, W.; JIANG, D.; SHIDONG, L.; JIN, M.; MCDONALD, B.A.; CERESINI, P.C. Genetic structure of populations of the rice-infecting pathogen Rhizoctonia solani AG-1 IA from China. Phytopathology, v. 99, p.1090-1099, 2009. DOI: 10.1094/ PHYTO-99-9-1090.

BRASIL. Decreto $\mathrm{n}^{\circ}$ 24.114, de 12 de abril de 1934. Aprova o Regulamento de Defesa Sanitária Vegetal. Diário Oficial [da] República Federativa do Brasil, Brasília, 4 maio 1934. Seção 1, p.8514.

BRASIL. Ministério da Agricultura, Pecuária e Abastecimento. Instrução normativa $n^{0}$ 52, de 20 de novembro de 2007. [Estabelece a lista de pragas quarentenárias ausentes (A1) e de pragas quarentenárias presentes (A2) para o Brasil e aprova os procedimentos para as suas atualizações]. Diário Oficial [da] República Federativa do Brasil, Brasília, 21 nov. 2007. Seção 1, p.31-34.

BRASIL. Ministério da Agricultura, Pecuária e Abastecimento. Portaria $n^{\circ} 11$, de 15 de fevereiro de 2002. [Credencia a Empresa 
Brasileira de Pesquisa Agropecuária - CENARGEN - Centro Nacional de Pesquisa de Recursos Genéticos e Biotecnologia como Estação Quarentenária nível 1, para os procedimentos legais exigidos para introdução de material propagativo no País]. Diário Oficial [da] República Federativa do Brasil, Brasília, 18 fev. 2002. Seção 1, p.6.

COMMONWEALTH AGRICULTURAL BUREAUX INTERNATIONAL. Index Fungorum. Disponível em: $<$ http:// www.indexfungorum.org/Names/Names.asp $>$. Acesso em: 12 maio 2009.

CHAVES, M.S.; MARTINELLI, J.A.; WESP, C. de L.; GRAICHEN, F.A.S. The cereal rusts: an overview. Pest Technology, v.2, p.38-55, 2008.

CHIORATO, A.F.; CARBONELL, S.A.M.; MOURA, R.R. de; ITO, M.F.; COLOMBO, C.A. Co-evolução entre raças fisiológicas de Colletotrichum lindemuthianum e feijoeiro. Bragantia, v.65, p.381-388, 2006.

DUNKLE, L.D. Milo disease. In: FREDERIKSEN, R.A. (Ed.). Compendium of sorghum diseases. St. Paul: APS, 1986. 82p.

ELLIS, M.B. Periconia circinata. CMI Descriptions of Pathogenic Fungi and Bacteria, v. 167, p.1-2, 1968.

SMITH, I.M.; MCNAMARA, D.G.; SCOTT, P.R.; HOLDERNESS, M. (Ed.). Quarantine pests for Europe: data sheets on quarantine pests for the European Union and for the European and Mediterranean Plant Protection Organization. $2^{\text {nd }}$ ed. Wallingford: CABI: EPPO, 1997. 1425p.

FERNANDES, R. de C.; EVANS, H.C.; BARRETO, R.W. Confirmation of the occurrence of teliospores of Hemileia vastatrix in Brazil with observations on their mode of germination. Tropical Plant Pathology, v.34, p.108-113, 2009. DOI: 10.1590/ S1982-56762009000200005.

GESSleR, C.; PERTOT, I.; PERAZZOLLI, M. Plasmopara viticola: a review of knowledge on downy mildew of grapevine and effective disease management. Phytopathologia Mediterranea, v.50, p.3-44, 2011. DOI: 10.14601/Phytopathol_ Mediterr-9360.

GONZÁLEZ-VERA, A.D.; BERNARDES-DE-ASSIS, J.; ZALA, M.; MCDONALD, B.A.; CORREA-VICTORIA, F.; GRATEROL-MATUTE, E.J.; CERESINI, P.C. Divergence between sympatric rice and maize-infecting populations of Rhizoctonia solani AG-1 IA from Latin America. Phytopathology, v.100, p.172-182, 2010. DOI: 10.1094/PHYTO-100-2-0172.

GRUZDEVIENĖ, E.; BRAZAUSKIENĖ, I.; REPEČKIENE், J.; LUGAUSKAS, A. The occurrence of pathogenic fungi during flax growing season in Central Lithuania. Journal of Plant Protection Research, v.48, p.255-266, 2008. DOI: 10.2478/ v10045-008-0029-2.

HANSO, M.; DRENKHAN, R. Lophodermium needle cast, insect defoliation and growth responses of young Scots pines in Estonia. Forest Pathology, v.42, p. 124-135, 2012. DOI: 10.1111/j.1439-0 329.2011.00728.x.

HENNING, A.A. Patologia e tratamento de sementes: noções gerais. 2.ed. Londrina: Embrapa Soja, 2005. 52p. (Embrapa Soja. Documentos, 264).
IMI DISTRIBUTION MAPS OF PLANT DISEASES. Wallingfrod: CAB International, Map n. 173, 1996.

INTERACTIVE Agricultural Ecological Atlas of Russia and Neighboring Countries. Economic Plants and their Diseases, Pests and Weeds. Disponível em: $<$ http://www.agroatlas.ru/en/content/diseases/ Oryzae/Oryzae_Ascochyta_oryzae/>.Acesso em: 15 jan. 2015.

INTERCÂMBIO comercial do agronegócio: principais mercados de destino. Brasília: MAPA, Secretaria de Relações Internacionais do Agronegócio, 2012. 456p. il.

LARTEY, R.T.; LENSSEN, A.W.; EVANS, R.G.; GHOSHROY, S. Comparative structural study of leaf spot disease of safflower and sugar beet by Cercospora beticola. Plant Pathotology Journal, v.6, 37-43, 2007. DOI: 10.3923/ppj.2007.37.43.

MANNINGER, S. Changes in virulence of rust fungi affecting wheat in Hungary. Novenyvedelem, v.44, p.328-332, 2008.

MARINHO, V.L. de A.; MENDES, M.A.S.; TENENTE, R.C.V.; BATISTA, M.F.; OLIVEIRA, M.R.V. de; MARQUES, A.S. dos A.; URBEN, A.F.; FONSECA, J.N.L.; GONZAGA, V. Procedimentos e métodos utilizados no intercâmbio e quarentena de germoplasma vegetal. Brasília: Embrapa Recursos Genéticos e Biotecnologia, 2003. 40p. (Embrapa Recursos Genéticos e Biotecnologia. Documentos, 103).

MARTINS, M.B.; VALENTE, J.P.; KOBAYASTI, L. GASPAROTTO, L. Progresso da sigatoka-negra (Mycosphaerella fijiensis) em bananeiras após a emissão do cacho no Município de Cáceres, Mato Grosso - Brasil. Summa Phytopathologica, v.33, p.309-312, 2007.

MEKONEN, M.; DILNESAW, Z. Assessment of diseases on soybean (Glycinmax L. merli) growing fields of Pawe and Dangur districts Metekel zone, Ethiopia. Wudpecker Journal of Agricultural Research, v.3, p.44-49, 2014.

MENDES, M.A.S.; FELIX, A.A.A.; SANTOS, M. de F.; HERNÁNDEZ GUTIÉRREZ, A. (Ed.). Fungos quarentenários para o Brasil. Brasília: Embrapa Recursos Genéticos e Biotecnologia, 2004. 325p.

MENDES, M.A.S.; FERREIRA, M.A.S.V. Fungos patogênicos detectados em germoplasma vegetal introduzido no Brasil de 1990 a 1992. Fitopatologia Brasileira, v.19, p.449-454, 1994.

MENDES, M.A.S.; URBEN, A.F.; DIANESE, J.C. Fungos em plantas no Brasil. 2.ed. rev. e ampl. Brasília: Embrapa SPI; Embrapa Recursos Genéticos e Biotecnologia, 2010. p.910.

MILLER, W.A.; ROY, K.W. Mycoflora of soybean leaves, pods, and seeds in Mississippi. Canadian Journal of Botany, v. 60, p. 2716-2723, 1982. DOI: 10.1139/b82-331.

MORDUE, J.E.M. Phoma exigua. CMI Descriptions of Plant Pathogenic Fungi and Bacteria, v.213, p.2, 1981.

NAGY, E.D.; BENNETZEN, J.L. Pathogen corruption and site-directed recombination at a plant disease resistance gene cluster. Genome Research, v.18, p.1918-1923, 2008. DOI: 10.1101/gr.078766.108.

NORTHAMERICANPLANTPROTECTIONORGANIZATIONS. Phytosanitary Alert System: Karnal bunt (Tilletia indica): amendment of the regulated areas in Arizona. 2013. Available at: 
$<$ http://www.pestalert.org/oprDetail.cfm?oprID=567>. Accessed on: 29 Nov. 2015.

SANSFORD, C.E.; BAKER; R.H.A.; BRENNAN, J.P.; EWERT, F.; GIOLI, B.; INMAN, A.; KINSELLA, A.; MAGNUS, H.A.; MIGLIETTA, F.; MURRAY, G.M.; PORTA-PUGLIA, A.; PORTER, J.R.; RAFOSS, T.; RICCIONI, L.; THORNE, F. The new Pest Risk Analysis for Tilletia indica, the cause of Karnal bunt of wheat, continues to support the quarantine status of the pathogen in Europe. Plant Pathology, v.57, p.603-611, 2008. DOI: 10.1111/j.1365-3059.2008.01825.x.

STONE, M. Virulent new strains of rust fungus endanger world wheat. Microbe, v.5, p.423-428, 2010. DOI: 10.1128/ microbe.5.423.1.

THOMAS, P. Weeds, insects and diseases protection. In: THOMAS, P. Canola growers manual. [S.1.]: Canola Council of Canada, 1984. p.1020-1062.
TIBOLLA, F.; SUMIDA, C.H.; PEITL, D.C.; CANTERI, M.G.; CASTRO, A.M.C. e. Métodos de preservação in vitro de urediniósporos de Puccinia kuehnii. Summa Phytopathologica, v.38, p.198-203, 2012.

TOMM, G.O. Situação em 2005 e perspectivas da cultura de canola no Brasil e em países vizinhos. Passo Fundo: Embrapa Trigo, 2005. 21p. (Embrapa Trigo. Boletim de pesquisa e desenvolvimento online, 26). Disponível em: $<$ http://ainfo.cnptia. embrapa.br/digital/bitstream/CNPT-2010/40299/1/p-bp26.pdf $>$. Acesso em: 15 dez. 2014.

WILLIAMS, T.H.; LIU, P.S.W. A host list of plant diseases in Sabah, Malaysia. Kew: CMI, 1976. 67p. (CMI. Phytopathological Paper, 19).

YORINORI, J.T.; LAZZAROTTO, J.J. Situação da ferrugem asiática da soja no Brasil e na América do Sul. Londrina: Embrapa Soja, 2004. 27p. (Embrapa Soja. Documentos, 236).

Recebido em 19 de dezembro de 2014 e aprovado em 22 de janeiro de 2016 